\title{
A Novel Buffering Technique for Aqueous Processing of Zinc Oxide Nanostructures and Interfaces, and Corresponding Improvement of Electrodeposited $\mathrm{ZnO}-\mathrm{Cu}_{2} \mathrm{O}$ Photovoltaics
}

\author{
Kevin P. Musselman,* Andrew Marin, Andreas Wisnet, Christina Scheu, \\ Judith L. MacManus-Driscoll,** and Lukas Schmidt-Mende**
}

A novel buffering method is presented to improve the stability of zinc oxide processed in aqueous solutions. By buffering the aqueous solution with a suitable quantity of sacrificial zinc species, the dissolution of functional zinc oxide structures and the formation of unwanted impurities can be prevented. The method is demonstrated for $\mathrm{ZnO}$ films and nanowires processed in aqueous solutions used for the selective etching of mesoporous anodic alumina templates and the electrochemical deposition of $\mathrm{Cu}_{2} \mathrm{O}$. In both cases, improved $\mathrm{ZnO}$ stability is observed with the buffering method. $\mathrm{ZnO}-\mathrm{Cu}_{2} \mathrm{O}$ heterojunction solar cells (bilayer and nanowire cells) synthesized using both traditional and buffered deposition methods are characterized by impedance spectroscopy and solar simulation measurements. Buffering the $\mathrm{Cu}_{2} \mathrm{O}$ deposition solution is found to reduce unwanted recombination at the heterojunction and improve the photovoltaic performance.

\section{Introduction}

$\mathrm{ZnO}$ is a wide-bandgap semiconductor $\left(E_{\mathrm{g}}=3.3 \mathrm{eV}\right)$ with a high electron mobility. ${ }^{[1]}$ It is an integral component of many emerging technologies in areas such as optoelectronics, energy harvesting, sensing, and catalysis. In photovoltaics for example, $\mathrm{ZnO}$ films have been used as charge blocking layers in organic solar cells, ${ }^{[2,3]} \mathrm{ZnO}$ nanowires have been used to improve charge collection in dye-sensitized and hybrid solar cells, ${ }^{[4-9]}$ and

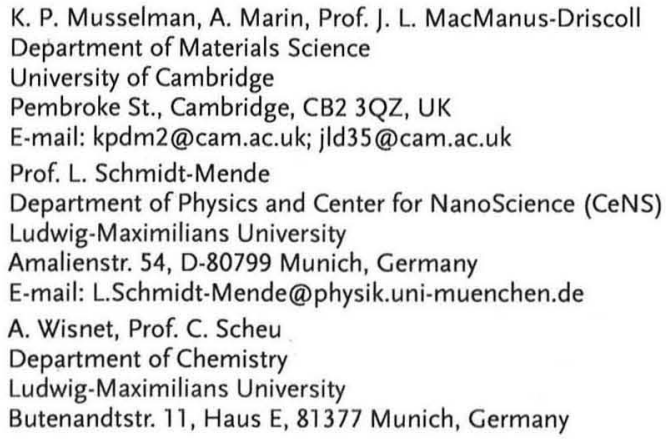

heterojunctions such as $\mathrm{ZnO}$-CdSe-CuSCN and $\mathrm{ZnO}-\mathrm{Cu}_{2} \mathrm{O}$ have been employed in inexpensive inorganic solar cells. ${ }^{[10-13]}$

While there has been much effort to synthesize functional $\mathrm{ZnO}$ structures by inexpensive, aqueous methods (e.g. electrodeposition, hydrothermal growth), the quality of the interfaces and nanostructures formed by the aqueous techniques has typically been overlooked. Consider the examples in Figure 1. In panel (a), a heterojunction is formed by electrochemical deposition onto a $\mathrm{ZnO}$ film or nanostructure from an aqueous solution, a technique used previously to synthesize photovoltaic devices. ${ }^{[10-13]}$ In panel (b), a surface treatment or coating is applied to a $\mathrm{ZnO}$ nanostructure using an aqueous solution. Plank et al. for example, reported a hydrothermal method for producing $\mathrm{MgO}$ shell coatings on $\mathrm{ZnO}$ nanowires, which involved soaking them for approximately $40 \mathrm{~min}$ in heated aqueous solutions. For $\mathrm{TiO}_{2}$, $\mathrm{TiCl}_{4}$ post treatments in heated aqueous solutions have been developed to tailor the conduction band edge ${ }^{[14]}$ and similar surface treatments may be developed for $\mathrm{ZnO}$. In Figure 1c, an aqueous etching solution is employed to remove a mesoporous template used for the formation of nanostructured $\mathrm{ZnO}$. Arrays of vertically-aligned metal oxide nanorods or nanowires are commonly synthesized in anodic alumina templates, which are typically removed using a basic, aqueous $\mathrm{NaOH}$ solution. ${ }^{[15-17]}$ For all of these examples, it is absolutely critical to consider the influence of the aqueous treatment on the morphology of the $\mathrm{ZnO}$ structures and the interfaces that they form.

Figure 2 illustrates a simplified electrochemical stability diagram for zinc and its oxide in aqueous solutions, constructed following the method of Pourbaix. ${ }^{[18]}$ This diagram indicates the thermodynamic regions of stability of the solid compounds (solid line), as well as the regions of predominance of the various dissolved species (thick dashed lines) and their solubility levels (thin dotted lines) in terms of $\log \left(\mathrm{mol} \mathrm{L}^{-1}\right)$. While the presence of other dissolved species in a particular aqueous solution may alter the equilibria of the zinc species from that expected for a pure aqueous solution, Figure 2 should nonetheless provide a good estimate of the stability of $\mathrm{ZnO}$ in various aqueous processing 


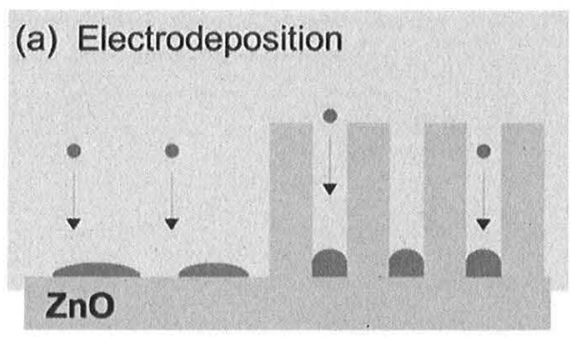

(b) Surface treatment or coating
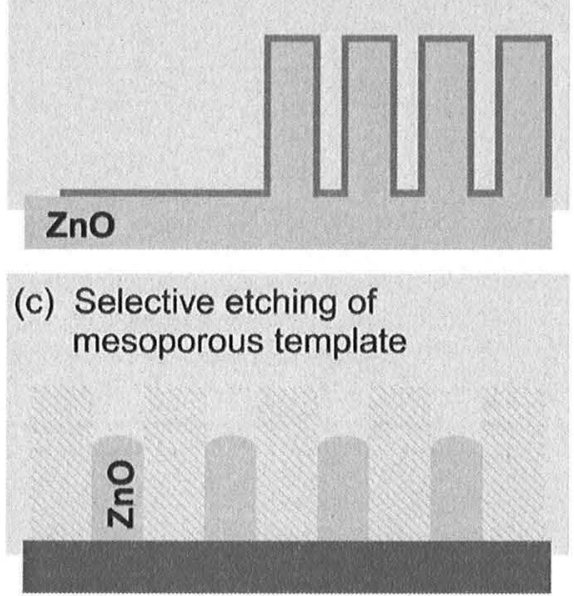

Figure 1. Common aqueous treatments applied to functional zinc oxide structures. a) Heterojunctions are formed by electrochemical deposition onto ZnO from aqueous solutions. b) Surface treatments and coatings are applied to $\mathrm{ZnO}$ in aqueous solutions. c) Aqueous etchants can be used to removed $\mathrm{ZnO}$ nanostructures from mesoporous templates.

solutions. In particular, it is noted that in basic solutions, dissolution of $\mathrm{ZnO}$ is expected according to the following reactions:

$\mathrm{ZnO}+\mathrm{H}_{2} \mathrm{O} \rightarrow \mathrm{HZnO}_{2}^{-}+\mathrm{H}^{+}$
$\mathrm{ZnO}+\mathrm{H}_{2} \mathrm{O} \rightarrow \mathrm{ZnO}_{2}^{2-}+2 \mathrm{H}^{+}$

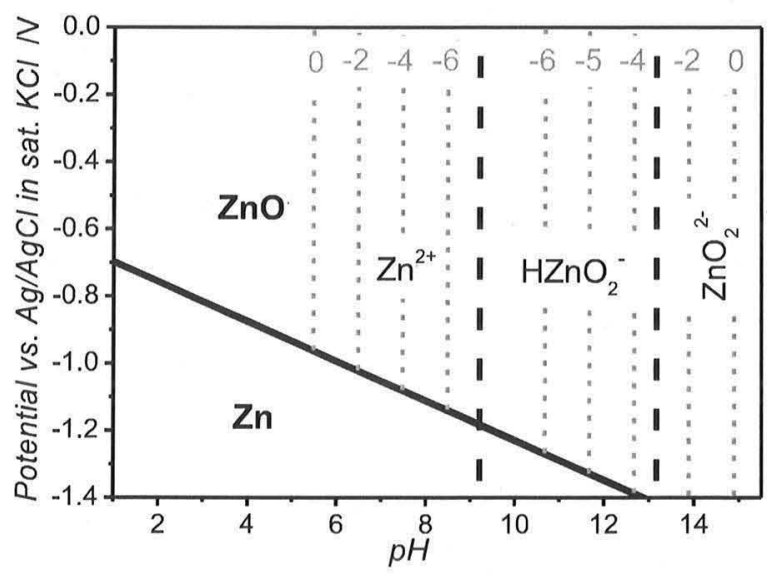

Figure 2. Simplified electrochemical stability diagram for $\mathrm{ZnO}$ in an aqueous solution at $25^{\circ} \mathrm{C}$. and in acidic solutions, $\mathrm{ZnO}$ dissolution is expected according to:

$\mathrm{ZnO}+2 \mathrm{H}^{+} \rightarrow \mathrm{Zn}^{2+}+\mathrm{H}_{2} \mathrm{O}$

In this work, the effect of typical aqueous processing solutions on the morphology of functional $\mathrm{ZnO}$ structures is examined. Aqueous treatments are shown to result in the dissolution of $\mathrm{ZnO}$ and the formation of unwanted precipitates on the $\mathrm{ZnO}$ surface. A novel buffering technique is introduced, whereby sacrificial zinc species are added to the aqueous processing solutions to establish electrochemical equilibrium and buffer the functional $\mathrm{ZnO}$ structures from unwanted dissolution. This method is found to dramatically improve the stability of functional $\mathrm{ZnO}$ under aqueous treatment.

To demonstrate the efficacy of this method, the buffering technique is applied to the electrochemical synthesis of $\mathrm{Cu}_{2} \mathrm{O}-\mathrm{ZnO}$ heterojunction solar cells from aqueous solutions. Inorganic solar cells electrodeposited from solutions near room temperature are extremely promising as ultra-low-cost, stable, non-toxic photovoltaics. $\mathrm{Cu}_{2} \mathrm{O}$ is a p-type semiconductor with a direct bandgap of approximately $2.0 \mathrm{eV}$ and a theoretical maximum power conversion efficiency of approximately $20 \%$, assuming only radiative recombination. ${ }^{[19,20]}$ Difficulty in doping $\mathrm{Cu}_{2} \mathrm{O}$ n-type has necessitated heterojunction architectures and $\mathrm{ZnO}$ been shown to be a suitable $n$-type counterpart.

In recent work, we showed that a nanowire (NW) architecture can be used to improve the minority carrier collection efficiency in electrodeposited $\mathrm{Cu}_{2} \mathrm{O}-\mathrm{ZnO}$ heterojunction solar cells. ${ }^{[13]}$ Although enhanced carrier collection was observed, the open-circuit voltage $V_{\mathrm{OC}}$ measured for the NW cells was approximately $0.2 \mathrm{~V}$. While this represented a significant improvement from most previous $\mathrm{Cu}_{2} \mathrm{O}-\mathrm{ZnO}$ nanowire cells, ${ }^{[12,21]}$ it is well below the built-in potential of around $0.7 \mathrm{~V}$ expected from the band offset of the materials. In this work, the low open-circuit voltage is attributed, at least in part, to a high density of interface states at the $\mathrm{Cu}_{2} \mathrm{O}-\mathrm{ZnO}$ heterojunction resulting from the aqueous synthesis. Such states facilitate unwanted recombination currents that oppose the photogenerated current. Impedance spectroscopy analysis of $\mathrm{Cu}_{2} \mathrm{O}-\mathrm{ZnO}$ heterojunctions synthesized with and without the buffering method indicate that the homogeneity of the interface and resistance to recombination are increased with the buffering method. The improved interface is shown to improve the $V_{\mathrm{OC}}$ and power conversion efficiency PCE of both bilayer and $\mathrm{NW} \mathrm{Cu}_{2} \mathrm{O}-\mathrm{ZnO}$ solar cells.

\section{A Novel Buffering Method for Processing $\mathrm{ZnO}$ in Aqueous Solutions}

Following from the electrochemical stability calculations of Pourbaix, ${ }^{[18]}$ the approximate solubility levels of the aqueous zinc species shown in Figure 2 are given in Table 1 as a function of the $\mathrm{pH}$ level. For $\mathrm{ZnO}$ immersed in an aqueous solution with a $\mathrm{pH}$ of 12.5 for example, Figure 2 indicates that $\mathrm{HZnO}_{2}^{-}$ is the predominant dissolved species, although a smaller quantity of $\mathrm{ZnO}_{2}{ }^{2-}$ will also be present. Table 1 indicates that $\mathrm{HZnO}_{2}{ }^{-}$should be produced via Equation 1 to attain an equilibrium concentration of approximately $10^{-4.2} \mathrm{~mol} \mathrm{~L}^{-1}$. Two 
Table 1. Solubility levels of zinc species in aqueous solutions at $25^{\circ} \mathrm{C} .{ }^{[18]}$

\begin{tabular}{lr}
\hline Aqueous species & Solubility Level $\left[\mathrm{mol} \mathrm{L}^{-1}\right]$ \\
\hline $\mathrm{Zn}^{2+}$ & $\log \left(\mathrm{Zn}^{2+}\right)=10.96-2 \mathrm{pH}$ \\
$\mathrm{HZnO}_{2}{ }^{-}$ & $\log \left(\mathrm{HZnO}_{2}^{-}\right)=-16.68+\mathrm{pH}$ \\
$\mathrm{ZnO}_{2}{ }^{2-}$ & $\log \left(\mathrm{ZnO}_{2}{ }^{2-}\right)=-29.78+2 \mathrm{pH}$ \\
\hline
\end{tabular}

aqueous processing solutions with $\mathrm{pH}$ levels of approximately 12.5 are studied as examples in this work: a $\mathrm{NaOH}$ solution for etching anodic alumina membranes and a $\mathrm{CuSO}_{4} /$ lactic acid/ $\mathrm{NaOH}$ solution for the electrodeposition of $\mathrm{Cu}_{2} \mathrm{O}$.

To prevent the unwanted dissolution of $\mathrm{ZnO}$, a suitable quantity of sacrificial $\mathrm{ZnO}$ powder was added to the aqueous processing solutions, which were then stirred and heated at $40{ }^{\circ} \mathrm{C}$ for several hours, prior to the insertion of the functional $\mathrm{ZnO}$ material. For example, for $40 \mathrm{~mL}$ of aqueous solution with a $\mathrm{pH}$ of 12.5 , approximately $8 \mathrm{mg}$ of $\mathrm{ZnO}$ powder was typically added, which corresponds to a $\mathrm{ZnO}$ concentration greater than $10^{-3} \mathrm{~mol} \mathrm{~L}^{-1}$. This should ensure that an equilibrium concentration of aqueous zinc species (particularly $\mathrm{HZnO}_{2}^{-}$) is achieved prior to insertion of the functional $\mathrm{ZnO}$, such that no further $\mathrm{ZnO}$ dissolution should occur.

For aqueous processing solutions with other $\mathrm{pH}$ levels, an appropriate quantity of $\mathrm{ZnO}$ powder with which to buffer the solution can be determined by selecting the predominant dissolved species from Figure 2 and its solubility level from Table 1. After heating and stirring the buffered solution, a small quantity of $\mathrm{ZnO}$ powder should remain, indicating that electrochemical equilibrium has been reached and further $\mathrm{ZnO}$ dissolution will be inhibited.

\subsection{Buffering of $\mathrm{NaOH}$ Etching Solution}

As illustrated in Figure 1c, aqueous $\mathrm{NaOH}$ etching solutions are typically used to selectively remove anodic alumina templates to leave free-standing nanostructures. ${ }^{[16,17]}$ In the basic etching solution, there is a strong affinity for the following reaction:

$\mathrm{Al}_{2} \mathrm{O}_{3}+\mathrm{H}_{2} \mathrm{O} \rightarrow 2 \mathrm{AlO}_{2}^{-}+2 \mathrm{H}^{+}$

resulting in dissolution of the anodic alumina template. For $\mathrm{ZnO}$ nanostructures synthesized using such templates, dissolution of the $\mathrm{ZnO}$ is also expected in the basic etching solution, according to Equations 1 and 2.

To examine the influence of the etching solution on $\mathrm{ZnO}$ nanostructures, free-standing $\mathrm{ZnO}$ nanowire arrays electrochemicallysynthesized from a zinc chloride solution were soaked in both a typical $0.1 \mathrm{~m} \mathrm{NaOH}$ etching solution and a buffered equivalent at room temperature. Approximately $35 \mathrm{~mL}$ of etching solution was used in both cases and approximately $9.5 \mathrm{mg}$ of $\mathrm{ZnO}$ powder was added to the buffered solution. The nanowire arrays were examined with scanning electron microscopy (SEM) before deposition, as well as after soaking for $2 \mathrm{~h}, 4 \mathrm{~h}$, and $8 \mathrm{~h}$ in the etching solutions. The etching solutions were replaced after $4 \mathrm{~h}$.

No change was visible by SEM in the nanowire array soaked in the buffered etching solution. Figure $3 a$ and c display the nanowire array after $4 \mathrm{~h}$ and $8 \mathrm{~h}$ in the buffered solution respectively. Smooth, straight nanowires are observed, typical of electrochemical growth. A considerable change in $\mathrm{ZnO}$ nanowire morphology, however, was observed for the nanowires soaked in the regular etching solution. Figure $3 \mathrm{~b}$ and $\mathrm{d}$ display the nanowire array after $4 \mathrm{~h}$ and $8 \mathrm{~h}$ in the buffered solution respectively. A clear decrease in nanowire uniformity is observed. The wires are rougher and notable variations in diameter are seen along their lengths. A reduction in typical nanowire diameter and increase in film porosity is observed with soaking in the regular solution, clearly indicating that dissolution of the $\mathrm{ZnO}$ nanowires occurs.

Depending on the thickness of the anodic alumina template, etching times of several hours may be necessary, such that significant damage to $\mathrm{ZnO}$ nanostructures can result. This novel buffering technique can be used to maintain the integrity of $\mathrm{ZnO}$ nanostructures during removal from anodic alumina templates. A pH of approximately 12.5 was measured for both solutions, and anodic alumina templates synthesized on indium-tin oxide (ITO)/glass substrates by a previously reported method ${ }^{[17]}$ were found to be efficiently etched by the buffered solution. This encouraging result suggests that the buffering technique should likewise improve the stability of $\mathrm{ZnO}$ in aqueous solutions used for treating or coating its surface.

\subsection{Buffering of $\mathrm{Cu}_{2} \mathrm{O}$ Electrodeposition Solution}

Similar improvements in stability were found for $\mathrm{ZnO}$ exposed to an aqueous $\mathrm{Cu}_{2} \mathrm{O}$ electrochemical deposition solution

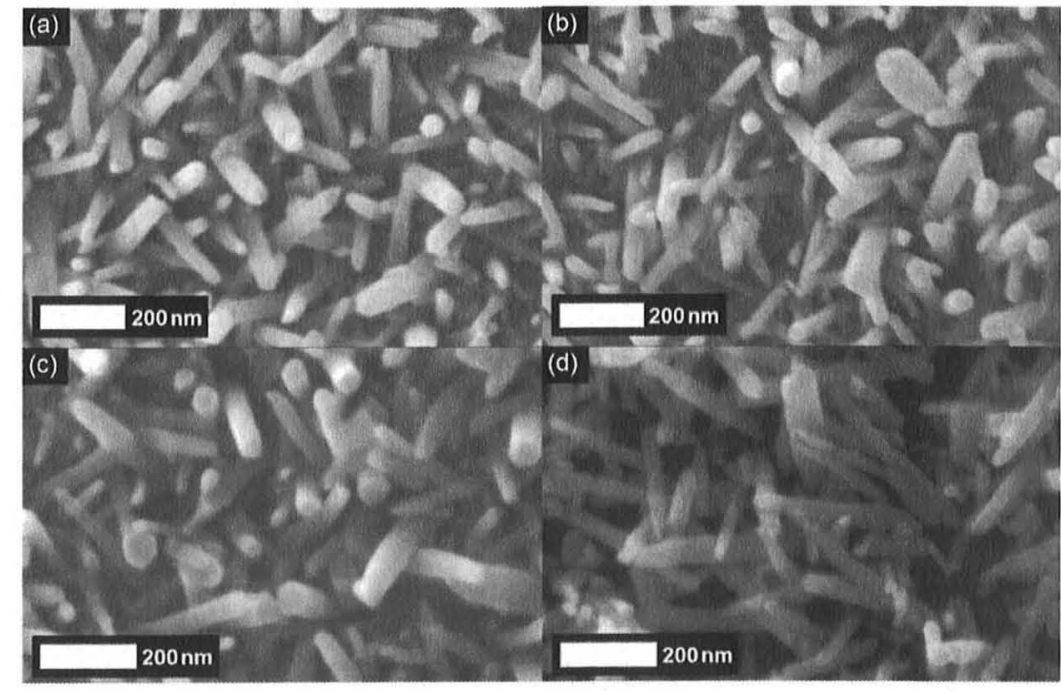

Figure 3. SEM images of $\mathrm{ZnO} N W \mathrm{~s}$ after soaking in a buffered $0.1 \mathrm{M}$ aqueous $\mathrm{NaOH}$ solution for $4 \mathrm{~h}$ (a) and $8 \mathrm{~h}$ (c), and after soaking in a regular $0.1 \mathrm{~m}$ aqueous $\mathrm{NaOH}$ solution for $4 \mathrm{~h}$ (b) and $8 \mathrm{~h}$ (d). Buffering of the $\mathrm{NaOH}$ solution with $\mathrm{ZnO}$ powder was found to dramatically reduce the dissolution of the NWs. 
(pH approximately 12.5) when the buffering technique was employed. Electrochemically grown $\mathrm{ZnO}$ nanowires were again exposed to the regular and buffered solutions, as were continuous $\mathrm{ZnO}$ films electrodeposited from zinc nitrate solutions. The etching of a $\mathrm{ZnO}$ film is demonstrated clearly in Figure 4. A SEM image of an as-deposited $\mathrm{ZnO}$ layer is shown in (a), and image (b) shows the same film after sitting in the regular $\mathrm{Cu}_{2} \mathrm{O}$ deposition solution for $1 \mathrm{~h}$. A typical $\mathrm{Cu}_{2} \mathrm{O}$ deposition takes approximately $30 \mathrm{~min}$, such that considerable etching of the $\mathrm{ZnO}$ films and nanowires will occur during device fabrication. Significant concentrations of the aqueous species $\left(\mathrm{HZnO}_{2}^{-}, \mathrm{ZnO}_{2}{ }^{2-}, \mathrm{H}^{+}\right)$are thus likely to be present on the $\mathrm{ZnO}$ surface and are liable to introduce a high concentration of interface states at the $\mathrm{Cu}_{2} \mathrm{O}-\mathrm{ZnO}$ heterojunction. These effects are expected to be much more significant for $\mathrm{Cu}_{2} \mathrm{O}$ deposition on NWs, where a larger ZnO surface area will result in more dissolution and a greater concentration of the aqueous species at the interface.

Etching of the $\mathrm{ZnO}$ cannot be avoided by instead depositing $\mathrm{ZnO}$ onto $\mathrm{Cu}_{2} \mathrm{O}$, as the electrochemical potential at which $\mathrm{ZnO}$ is deposited (approximately $-1 \mathrm{~V}$ versus $\mathrm{Ag} / \mathrm{AgCl}$ ) is liable to reduce $\mathrm{Cu}_{2} \mathrm{O}$ to $\mathrm{Cu}^{[18]}$ To limit $\mathrm{ZnO}$ dissolution and the formation of undesirable interface states during device fabrication, the buffering technique was employed. For every $100 \mathrm{~mL}$ of $\mathrm{CuSO}_{4} /$ lactic acid/NaOH solution, approximately $25 \mathrm{mg}$ of $\mathrm{ZnO}$ powder was added.

Figure 4c shows a SEM image of a $\mathrm{ZnO}$ film after soaking for $1 \mathrm{~h}$ in this buffered solution. The $\mathrm{ZnO}$ powder was found to drastically reduce the $\mathrm{ZnO}$ etching in the $\mathrm{Cu}_{2} \mathrm{O}$ solution. Figure $4 \mathrm{~d}$ shows a bright-field transmission electron microscopy (TEM) image of $\mathrm{ZnO}$ nanowires that were etched for $15 \mathrm{~min}$

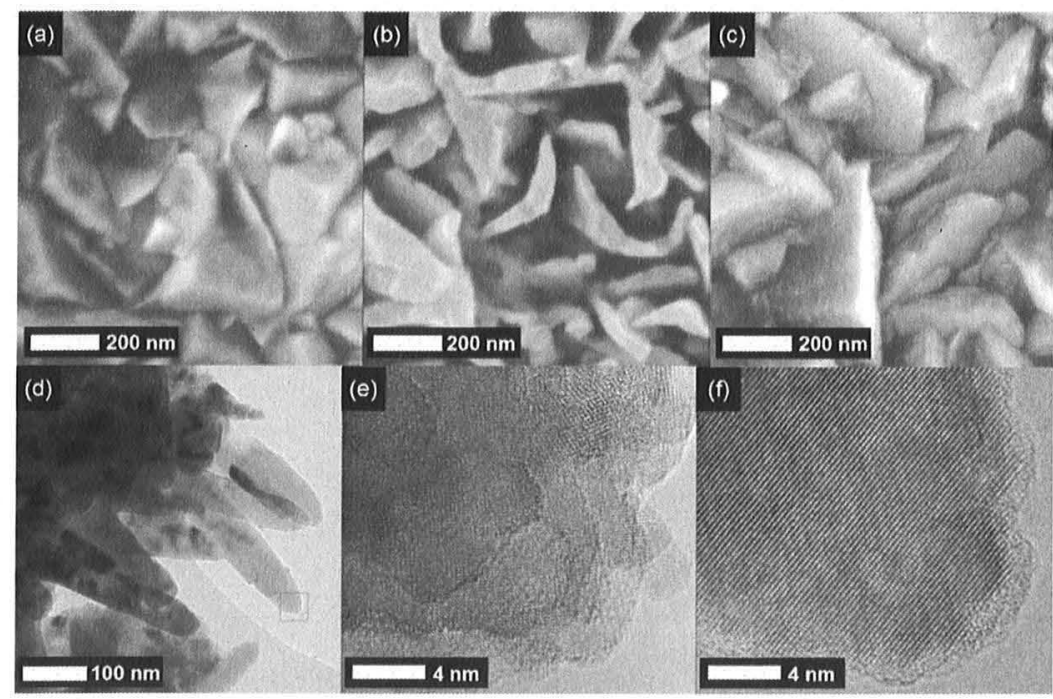

Figure 4. SEM images of $\mathrm{ZnO}$ films as-deposited (a), and after sitting for $1 \mathrm{~h}$ in a regular $\mathrm{Cu}_{2} \mathrm{O}$ deposition solution (b) and buffered $\mathrm{Cu}_{2} \mathrm{O}$ deposition solution (c). Buffering of the $\mathrm{Cu}_{2} \mathrm{O}$ solution with $\mathrm{ZnO}$ powder was found to dramatically reduce the etching of the underlying $\mathrm{ZnO}$ during $\mathrm{Cu}_{2} \mathrm{O}$ deposition. d) Bright-field TEM and (e) HRTEM images of $\mathrm{ZnO}$ nanowires that were etched in a regular $\mathrm{Cu}_{2} \mathrm{O}$ electrodeposition solution for $15 \mathrm{~min}$. Surface steps are visible on the wire surface in (e), suggesting that etching of the $\mathrm{ZnO}$ takes place. $\mathrm{f}$ ) A similar HRTEM image of a nanowire tip that was etched in a buffered $\mathrm{Cu}_{2} \mathrm{O}$ solution for 15 min shows no surface step features. in regular $\mathrm{Cu}_{2} \mathrm{O}$ electrodeposition solution then scraped off the sample surface. A high-resolution TEM (HRTEM) image of one of the nanowire tips in Figure 4d (highlighted by a dashed rectangle) is shown in Figure 4e. HRTEM imaging indicated that the wires were single crystalline. The dark rims in Figure $4 \mathrm{e}$ indicate the presence of surface steps on the wire, which may correspond to the etching of the wire surface. Figure $4 \mathrm{f}$ shows a similar HRTEM image of a nanowire scraped from a sample that was instead soaked for $15 \mathrm{~min}$ in a buffered $\mathrm{Cu}_{2} \mathrm{O}$ elecrodeposition solution. A single crystal structure is again evident. No surface step features are observed for this nanowire, indicating that dissolution of the $\mathrm{ZnO}$ was inhibited by buffering the $\mathrm{Cu}_{2} \mathrm{O}$ deposition solution. It should be noted that the removal of material from the nanowires may be due in part to TEM beam damage. Damage was noted for both samples after extended study in the TEM. However, the surface steps of the sample etched in the regular solution were present from the beginning, strongly suggesting that they were due to the chemical treatment.

The $\mathrm{ZnO}$ dissolution resulting from exposure to the $\mathrm{Cu}_{2} \mathrm{O}$ deposition solutions was also examined using X-ray diffraction (XRD). A pristine $\mathrm{ZnO}$ film was first analyzed; other than peaks corresponding to the ITO substrate, only $\mathrm{ZnO}$ reflections were observed. The sample was then cleaved in two. One half was soaked for $45 \mathrm{~min}$ in regular $\mathrm{Cu}_{2} \mathrm{O}$ deposition solution, and the other for the same duration in a buffered solution. Following this, the samples were thoroughly rinsed with distilled water, dried with nitrogen gas, and re-examined using XRD. Figure 5a shows the XRD data for the two samples. The sample soaked in the buffered solution was unchanged, whereas a significant decrease in the relative intensities of the $\mathrm{ZnO}$ peaks is observed for the film soaked in the regular $\mathrm{Cu}_{2} \mathrm{O}$ deposition solution, clearly indicating the dissolution of $\mathrm{ZnO}$.

Several small, additional peaks were also noted in the XRD data for the film soaked in the regular $\mathrm{Cu}_{2} \mathrm{O}$ deposition solution. These peaks are attributable to a number of species that may precipitate from the solution, including sodium hydroxide, copper sulfate, copper oxide sulfate, and copper (II) oxide. Figure $5 \mathrm{~b}$ shows a SEM image of precipitates formed on the $\mathrm{ZnO}$ surface. Energy-dispersive X-ray (EDX) analysis of these precipitates indicated a 1:1 atomic ratio of $\mathrm{Cu}: \mathrm{O}$, in agreement with the copper (II) oxide peak observed in the XRD. It is likely that the roughened film surface that results from $\mathrm{ZnO}$ etching inhibits the removal of these precipitates during rinsing. It is also possible that the aqueous species formed by the dissolution of the $\mathrm{ZnO}$ may mediate the precipitation of these impurities. In any case, no such precipitates were detected for the $\mathrm{ZnO}$ samples soaked in the buffered solution.

Cyclic voltammetry measurements were performed on both the regular and buffered $\mathrm{Cu}_{2} \mathrm{O}$ deposition solutions and were found to be identical, indicating that the small 

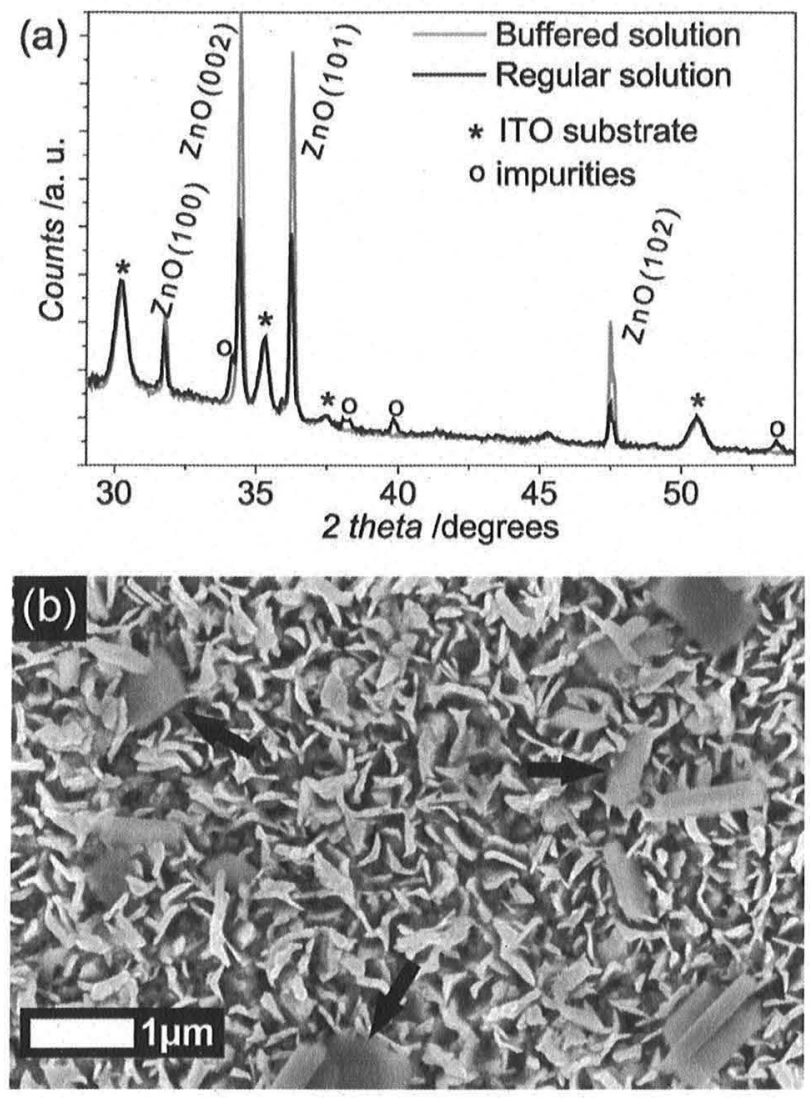

Figure 5. (a) XRD data of $\mathrm{ZnO}$ films soaked for $45 \mathrm{~min}$ in a regular and buffered $\mathrm{Cu}_{2} \mathrm{O}$ electrodeposition solution. Buffering with $\mathrm{ZnO}$ powder is seen to prevent the dissolution of $\mathrm{ZnO}$ in the basic solution and the formation of unwanted impurities. (b) SEM image of impurities (highlighted with arrows) formed on the $\mathrm{ZnO}$ film surface when it was soaked in regular $\mathrm{Cu}_{2} \mathrm{O}$ deposition solution.

concentration of zinc species has little influence on the $\mathrm{Cu}_{2} \mathrm{O}$ deposition dynamics. Furthermore, no zinc impurities were detected by $\mathrm{EDX}$ in $\mathrm{Cu}_{2} \mathrm{O}$ films synthesized using the buffered solution, indicating negligible incorporation of zinc impurities.

\section{3. $\mathrm{Cu}_{2} \mathrm{O}-\mathrm{ZnO}$ Heterojunctions Synthesized Using Buffered $\mathrm{Cu}_{2} \mathrm{O}$ Deposition Solutions}

The importance of the buffering method presented in this work has been further demonstrated by employing it in the electrochemical synthesis of $\mathrm{Cu}_{2} \mathrm{O}-\mathrm{ZnO}$ solar cells. Both simple bilayer and $\mathrm{NW} \mathrm{Cu}_{2} \mathrm{O}-\mathrm{ZnO}$ heterojunctions were fabricated by electrodeposition of $\mathrm{ZnO}$ and $\mathrm{Cu}_{2} \mathrm{O}$ onto commercial ITO/ glass substrates. The device structures are shown in Figure 6. $\mathrm{ZnO}$ films and nanowires were deposited using zinc nitrate ${ }^{[22]}$ and zinc chloride ${ }^{[23]}$ solutions respectively. The $\mathrm{ZnO}$ films were polycrystalline, with a hexagonal wurtzite structure. The $\mathrm{ZnO}$ nanowire arrays were grown on a $50 \mathrm{~nm} \mathrm{Zn}$ seed layer. The wires were disordered but highly crystalline, again with a wurtzite structure. The light-absorbing $\mathrm{Cu}_{2} \mathrm{O}$ layer was electrodeposited

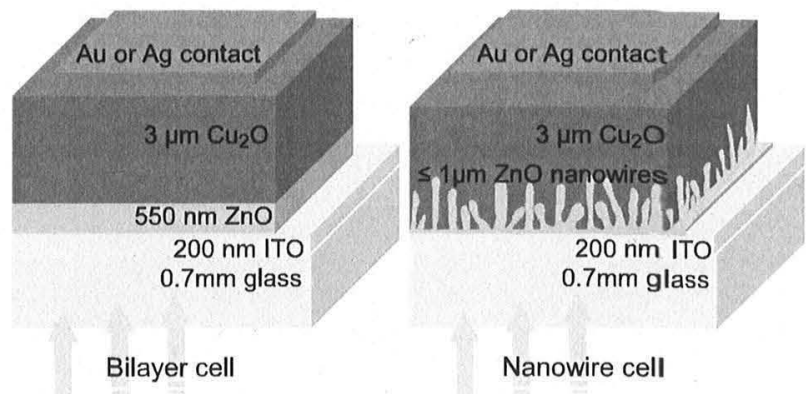

Figure 6. Schematic illustrations of bilayer and $\mathrm{NW} \mathrm{Cu}_{2} \mathrm{O}-\mathrm{ZnO}$ heterojunction solar cells studied in this work.

on the $\mathrm{ZnO}$ films and NW arrays using a $\mathrm{CuSO}_{4}(0.4 \mathrm{M}) /$ lactic $\operatorname{acid}(3 \mathrm{~m})$ solution, to which a similar amount of $4 \mathrm{~m} \mathrm{NaOH}$ was added to adjust the $\mathrm{pH}$ to approximately $12.5 \cdot \cdot^{[19,20,24]}$ Both regular and buffered versions of the $\mathrm{Cu}_{2} \mathrm{O}$ deposition solution were employed. The $\mathrm{Cu}_{2} \mathrm{O}$ and $\mathrm{ZnO}$ layers used were typically $3 \mu \mathrm{m}$ and $550 \mathrm{~nm}$ thick respectively, and the $\mathrm{ZnO}$ nanowires had lengths up to approximately $1 \mu \mathrm{m}$ and diameters ranging from $20 \mathrm{~nm}$ to over $200 \mathrm{~nm}$. Typical deposition times were 10 and $45 \mathrm{~min}$ for the $\mathrm{ZnO}$ films and nanowires, and $30 \mathrm{~min}$ for the $\mathrm{Cu}_{2} \mathrm{O}$ layers.

The influence of buffering the $\mathrm{Cu}_{2} \mathrm{O}$ deposition solution on the properties of the electrochemically synthesized heterojunctions was examined using impedance spectroscopy and related to solar simulation measurements.

\subsection{Impedance Spectroscopy}

Impedance spectroscopy is a powerful tool for the electrical characterization of interfaces and composite structures, and has been used extensively to characterize the properties of solid state solar cells. ${ }^{[25-27]}$ Impedance measurements were conducted in the dark under different applied biases ranging from $0 \mathrm{~V}$ to $0.5 \mathrm{~V}$ and the frequency was swept from $40 \mathrm{~Hz}$ to $1 \mathrm{MHz}$ with a $20 \mathrm{mV}$ AC voltage perturbation.

Nyquist plots of bilayer heterojunctions synthesized using regular and buffered $\mathrm{Cu}_{2} \mathrm{O}$ deposition solutions are shown in Figure $7 \mathrm{a}$ and $\mathrm{b}$, respectively, at various applied biases. The corresponding Bode plots are included in Figure S1 of the Supporting Information. The Nyquist plots consist of a large, low-frequency arc, typical of p-n junctions. Such junctions are traditionally modeled by an equivalent circuit consisting of a resistor in series with a parallel combination of a resistor and a capacitor. ${ }^{[25-27]}$ The series resistor describes the resistance of the collection electrodes and the parallel resistor characterizes leakage and recombination paths through the cell. The parallel capacitor represents the capacitance resulting from the depletion region of the $p-n$ junction.

Figure $7 d$ shows a magnified view of the high-frequency data for the buffered device from Figure $7 \mathrm{~b}$. A second, highfrequency arc is observed. This additional arc was likewise observed for the device synthesized using the regular $\mathrm{Cu}_{2} \mathrm{O}$ deposition solution. Impedance spectra consisting of two arcs have been observed previously for CdTe solar cells, where the 

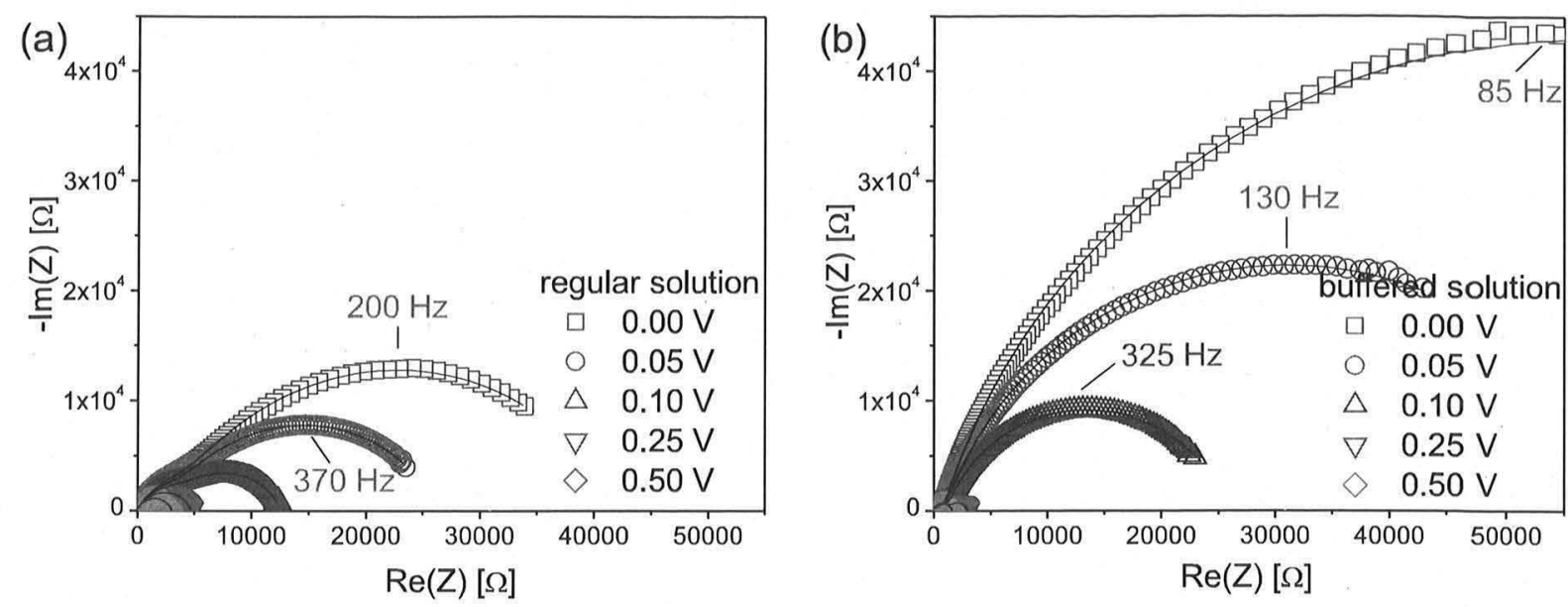

(c)

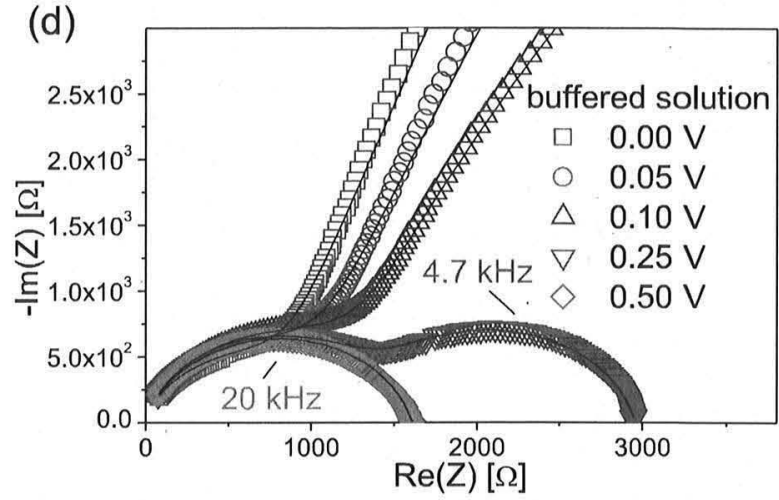

Figure 7. Impedance spectra for bilayer heterojunctions synthesized with regular (a) and buffered (b) $\mathrm{Cu}_{2} \mathrm{O}$ deposition solutions. (c) The equivalent circuit used to fit the data, where constant phase elements are used to account for surface inhomogeneities resulting from roughness and interfacial states. Data fits to impedance spectra are indicated by solid lines. (d) High-frequency impedance data for the buffered cell indicates a second arc due to a Schottky barrier at the ITO-ZnO interface.

high-frequency feature was attributed to a Schottky contact at one of the electrodes. ${ }^{[28,25,27]}$ The high-frequency feature observed here was likewise attributed to a Schottky barrier at the ZnO-ITO interface. Figure S2 in the Supporting Information shows Nyquist plots of electrodeposited ZnO films on ITO with $\mathrm{Ag}$ and $\mathrm{Au}$ top contacts, without a $\mathrm{Cu}_{2} \mathrm{O}$ layer. While the low-frequency arc corresponding to the $\mathrm{Cu}_{2} \mathrm{O}-\mathrm{ZnO}$ heterojunction is no longer present, the high-frequency arc remains, confirming that it originates from the interface between the $\mathrm{ZnO}$ and contact electrode. No such features were observed when $\mathrm{Cu}_{2} \mathrm{O}$ films deposited on ITO with $\mathrm{Au}$ or Ag top contacts were measured.

The impedance spectra in Figure 7 are not perfect semicircles. The arcs are compressed, with centers of radius below the $\operatorname{Re}(\mathrm{Z})$ axis. This behavior is known to result from inhomogeneities in the electrical properties of the measured interface. ${ }^{[29]}$ Such inhomogeneities include roughness and interface states (charge trap levels near the interface) induced by defects and impurities. ${ }^{[30,27]}$ In previous impedance studies of solar cells, additional circuit elements have been included to account for discrete trap levels at heterojunctions. ${ }^{[31,32,27]}$ In the simplest case, the presence of one trap level can be represented in an equivalent circuit by a series RC component associated with the charging and discharging time characteristic for the given trap level, as shown in Figure 8a where $R_{\mathrm{IS}}$ and $C_{\mathrm{IS}}$ are the resistance and capacitance associated with the trap level. Typically there may be multiple trapping states at the heterojunction interface with a significant spread in time constants, which give rise to multiple circuit elements as shown in Figure 8b. To account for this distribution in electrical properties at the interface, a Constant Phase Element (CPE) can be used in lieu of a simple capacitor, as shown in Figure 8c. ${ }^{[33,29,34,27]}$ The impedance of the CPE is defined as:

$\tilde{Z}(\omega)=\frac{1}{(\mathrm{Q} \omega t)^{\varphi}}$

where $\omega$ is the frequency and $\varphi$ is a fitting parameter with a value between 0 and 1 . When $\varphi$ is 1 , the element is an ideal capacitor with the capacitance equal to $Q$. As the homogeneity of the interface decreases, $\varphi$ is expected to deviate further from 1.

Figure 7c shows the equivalent circuit to which the impedance data was fit. The fits are indicated by solid lines in the plots and showed good agreement with the data, confirming the suitability of the equivalent circuit model used. Circuit 
(a)

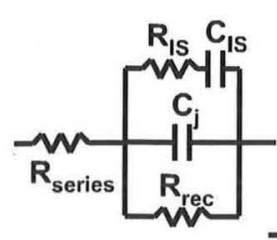

(b).

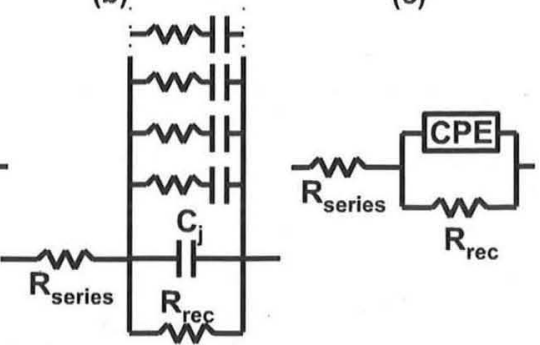

Figure 8. Equivalent circuits for (a) a heterojunction with a single trapping state of time constant $R_{\mathrm{IS}} C_{\mathrm{IS}}$ and (b) a heterojunction with a distribution of trap states of varying time characteristic. (c) A constant phase element can be used to describe the distributed nature of a heterojunction with a variety of interfacial states.

parameters obtained from a complex nonlinear least-squares fitting program ${ }^{[35]}$ are summarized in Table S1 in the Supporting Information. Fitted $R_{\text {series }}$ values were negligible for the bilayer heterojunctions and thus have not been included in the table.

The fitted values of $R_{\text {rec }}$ are plotted in Figure 9 as a function of the bias voltage for both the buffered and regular bilayer heterojunctions. For a solar cell under bias, a dark current results, which flows in a direction opposing the photogenerated current. For a lattice-mismatched heterojunction such as $\mathrm{Cu}_{2} \mathrm{O}-\mathrm{ZnO}$, this dark current is expected to result from recombination at the interface (holes from the $\mathrm{Cu}_{2} \mathrm{O}$ recombine with electrons from the $\mathrm{ZnO}){ }^{\left[{ }^{[36]}\right.} R_{\text {rec }}$ provides a measure of the resistance to this recombination at the $\mathrm{Cu}_{2} \mathrm{O}-\mathrm{ZnO}$ interface. $R_{r e c}$ was found to decrease with bias voltage as expected, as the potential barrier to tunnelling or carrier injection at the interface is reduced. Notably, a larger resistance to recombination was observed for

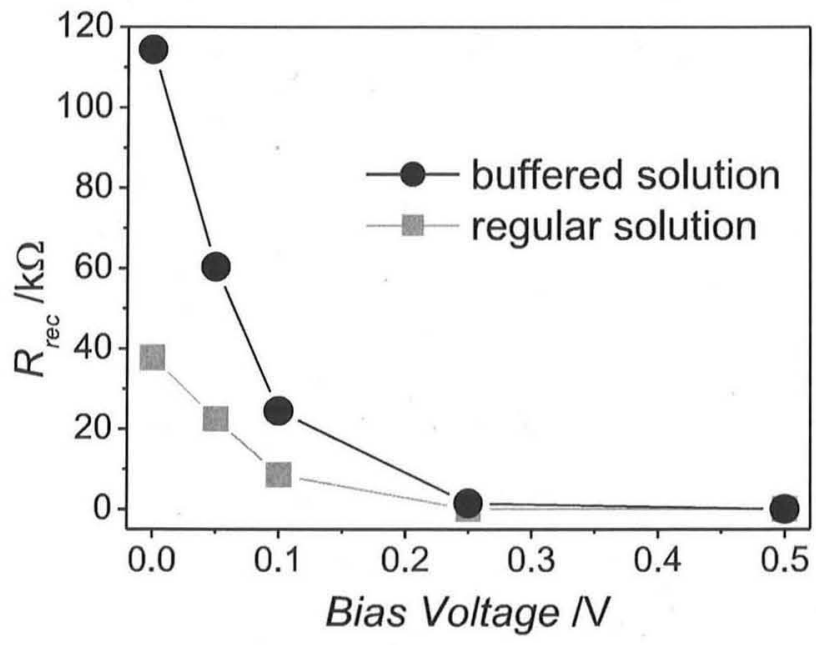

Figure 9. $R_{\text {rec }}$ values obtained by complex nonlinear least-squares fitting of bilayer $\mathrm{Cu}_{2} \mathrm{O}-\mathrm{ZnO}$ heterojunction impedance data. The buffered device displayed larger values for the recombination resistance, suggesting a smaller density of defect states, which act as recombination centers at the $\mathrm{Cu}_{2} \mathrm{O}-\mathrm{ZnO}$ interface. the bilayer device synthesized using the buffered solution. This suggests that a smaller density of defect states, which act as recombination centers, exist at the buffered interface. Correspondingly, the characteristic frequencies of the low-frequency impedance arcs in Figure 7 are lower for the buffered cell, indicating a slower recombination rate at the buffered $\mathrm{Cu}_{2} \mathrm{O}-\mathrm{ZnO}$ interface.

The CPE parameter $\varphi 2$ characterizes the dispersion of time constants at the $\mathrm{Cu}_{2} \mathrm{O}-\mathrm{ZnO}$ interface, as described in Equation 5. $\varphi 2$ values obtained from spectra with prominent low-frequency impedance arcs well suited for fitting are given in Table 2. Standard deviations determined by the fitting routine are given in the table as error bounds. The lower $\varphi 2$ values observed for the unbuffered device indicate a more inhomogeneous interface, which may be attributed to both a rougher heterojunction resulting from $\mathrm{ZnO}$ dissolution and a greater density of interface states with varying energy levels.

Interface states are known to influence the built-in potential $\left(V_{b i}\right)$ of a diodeand hence its photovoltaic properties. ${ }^{[37]}$ Figure 10a illustrates the approximate energy levels of a $\mathrm{Cu}_{2} \mathrm{O}-\mathrm{ZnO}$ heterojunction. For typical majority carrier concentrations of $10^{14} \mathrm{~cm}^{-3}$ and $10^{18} \mathrm{~cm}^{-3}$ in electrodeposited $\mathrm{Cu}_{2} \mathrm{O}^{[24]}$ and $\mathrm{ZnO}^{[22]}$ films respectively, a $V_{b i}$ of approximately $0.7 \mathrm{~V}$ is expected at the heterojunction, which corresponds to the difference in Fermi energies of the two materials and provides an estimate of the achievable open-circuit voltage. The reported open-circuit voltages of electrodeposited bilayer $\mathrm{Cu}_{2} \mathrm{O}-\mathrm{ZnO}$ solar cells, however, vary widely (i.e., 0.19 to $0.59 \mathrm{~V}$ ), which may be due in part to varying concentrations of interface states. ${ }^{[11,22,38]}$

If a significant number of states exist at the interface and act as acceptors, electrons may be removed from the depletion region, bending the energy bands upwards, as shown in Figure 10b. As the carrier concentration is much higher in the electrodeposited $\mathrm{ZnO}$, the built-in potential is expected to be formed predominantly in the $\mathrm{Cu}_{2} \mathrm{O}\left(V_{b i}(\mathrm{p})>V_{b i}(\mathrm{n})\right)$. Upward band bending in the $\mathrm{Cu}_{2} \mathrm{O}$ near the interface would therefore drastically reduce the built-in potential of the diode. Holes from the $\mathrm{Cu}_{2} \mathrm{O}$ could more easily reach the interface and recombine, reducing the achievable $V_{\mathrm{OC}}$. Trap levels near the interface could likewise facilitate carrier tunneling to the interface for recombination. The increased resistance to recombination at the $\mathrm{Cu}_{2} \mathrm{O}-$ $\mathrm{ZnO}$ interface that was observed here for the buffered heterojunction has been attributed to a reduction in the interface state density. The influence of this reduction in interface state density on the photovoltaic performance of the heterojunctions is examined in the following section.

Table 2. Fitted $\varphi 2$ values for bilayer heterojunctions (standard deviations from the fitting routine indicated by error bounds).

\begin{tabular}{lcc}
\hline Bias & \multicolumn{2}{c}{$\varphi 2$} \\
\cline { 2 - 3 }$[\mathrm{V}]$ & Regular heterojunction & Buffered Heterojunction \\
\hline 0.00 & $0.75 \pm 0.01$ & $0.82 \pm 0.01$ \\
0.05 & $0.75 \pm 0.01$ & $0.81 \pm 0.01$ \\
0.10 & $0.78 \pm 0.01$ & $0.81 \pm 0.01$ \\
0.25 & & $0.87 \pm 0.01$ \\
\hline
\end{tabular}


(a)

(b)

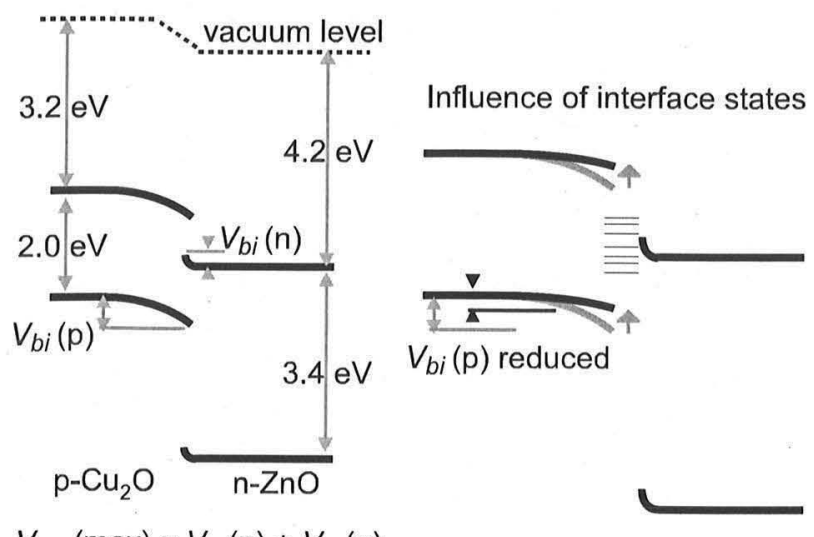

$V_{O C}(\max ) \approx V_{b i}(\mathrm{p})+V_{b i}(\mathrm{n})$

Figure 10. (a) $\mathrm{Cu}_{2} \mathrm{O}-\mathrm{ZnO}$ heterojunction at equilibrium. $V_{b i}(\mathrm{p})$ and $V_{b i}(\mathrm{n})$ represent the portions of the diode built-in potential formed in the $\mathrm{Cu}_{2} \mathrm{O}$ and $\mathrm{ZnO}$ respectively. The achievable $V_{\mathrm{OC}}$ is expected to increase with the total built-in potential of the diode $\left(V_{b i}=V_{b i}(p)+V_{b i}(n)\right)$, which acts as a barrier to recombination currents in a heterojunction solar cell. (b) Interface states can influence the distribution of charges at the interface, reducing the built-in potential and limiting the achievable $V_{\mathrm{Oc}}$.

\subsection{Solar Cell Performance}

To examine the influence of the buffering method on the performance of electrochemically-synthesized $\mathrm{Cu}_{2} \mathrm{O}-\mathrm{ZnO}$ photovoltaics, the current density-voltage $J-V$ characteristics of bilayer and $\mathrm{NW} \mathrm{Cu}_{2} \mathrm{O}-\mathrm{ZnO}$ solar cells synthesized using both the traditional and buffered $\mathrm{Cu}_{2} \mathrm{O}$ deposition methods were examined under simulated AM 1.5G solar illumination $\left(100 \mathrm{~mW} \mathrm{~cm} \mathrm{~cm}^{-2}\right)$. For both geometries, device performance was found to improve when the buffering technique was used.

Figure 11 a displays solar simulator data for the bilayer heterojunctions. The devices were measured as-deposited, one week after their synthesis. The buffered solution is seen to increase both the $V_{\mathrm{OC}}$ and the fill factor $F F$ of the bilayer device, while the short-circuit current density $J_{\mathrm{SC}}$ is relatively unchanged, resulting in an increase in the PCE from $0.50 \%$ to $0.65 \%$. This result is consistent with a decrease in the interface state density at the heterojunction. Following from Figure 10b, it is expected that a reduction in interface state density should limit unwanted band bending and carrier recombination, resulting in a higher $V_{\mathrm{OC}}$, while leaving the $J_{\mathrm{SC}}$ relatively unchanged. Dark $J-V$ measurements of the bilayer cells are included in Figure S3a of the Supporting Information. A reduction in the reverse bias current is observed with buffering, consistent with the increased recombination resistance observed by impedance spectroscopy. The reduced reverse saturation current and increased recombination resistance measured in the dark are also consistent with the observed increase in $V_{\text {OC. }}$. However, it is difficult to directly correlate these measurements performed in the dark with device properties under illumination, due to the photoconductive nature of the materials. The photoconductivity of $\mathrm{Cu}_{2} \mathrm{O}$, for example, has been attributed to deep minority carrier trapping centers that become filled during illumination. ${ }^{[39]}$ Transport properties of the devices will therefore vary with illumination. Future impedance and $J-V$ studies of the devices after illumination will permit more detailed comparison.

It is noted that the PCEs measured for the bilayer heterojunctions here are less than the highest value previously reported in the literature $(1.28 \%)$, due to a higher $V_{\mathrm{OC}}(0.59 \mathrm{~V})$ measured in that work. ${ }^{[1]}$ Thus while the reduction in interface states resulting from aqueous processing is an important step in improving the performance of electrochemically-synthesized solar cells, other interfacial properties such as roughness and crystallographic orientation certainly influence the $V_{\mathrm{OC}}$ of the $\mathrm{Cu}_{2} \mathrm{O}-\mathrm{ZnO}$ heterojunctions in this study and warrant further optimization.

Figure $11 \mathrm{~b}$ displays solar simulator data for NW heterojunctions synthesized using both the traditional and buffered $\mathrm{Cu}_{2} \mathrm{O}$ deposition solutions. The heterojunctions synthesized using the traditional $\mathrm{Cu}_{2} \mathrm{O}$ deposition solution typically demonstrated a negligible photovoltaic effect in their as-deposited form. Postdeposition annealing at $100{ }^{\circ} \mathrm{C}$ on a hotplate was required for several hours in order to observe rectification and a photovoltaic effect in these cells. The unbuffered NW cell in Figure 11b was annealed for $5 \mathrm{~h}$ at $100^{\circ} \mathrm{C}$.

NW cells fabricated using the buffering technique, on the other hand, did not typically require annealing. The NW cell in Figure $11 \mathrm{~b}$ that was synthesized using the buffering method was measured after sitting in air for approximately 2 weeks, with no thermal treatment. This suggests that annealing is required in the traditional devices to accelerate the passivation of a high density of interface states. As these heterojunctions are intended as ultra-low-cost cells to be fabricated on various conducting substrates, the elimination of the annealing requirement is a considerable advantage of the buffering method presented there.

As a greater density of interface states is expected for the large-area nanowire heterojunction, more significant improvement is expected with the buffering technique. The $V_{\mathrm{OC}}$ and $F F$ of the nanowire cells increased by $27 \%$ and $18 \%$, respectively, with buffering, compared to $16 \%$ and $15 \%$ increases in the bilayer devices. Likewise, the reduction in the reverse bias current for the buffered NW cell was larger than that observed for the buffered bilayer cell, even though the buffered NW device was annealed for a shorter duration than the equivalent unbuffered cell (see Figure S3b of the Supporting Information).

A slight reduction in $J_{\mathrm{SC}}$ is observed for the buffered NW cell. This can be attributed to the fact that the NW heterojunction synthesized from the traditional solution required annealing for $5 \mathrm{~h}$, whereas the buffered device could be measured as deposited. In previous work on $\mathrm{Cu}_{2} \mathrm{O}-\mathrm{ZnO} \mathrm{NW}$ heterojunctions, it was found that annealing the cells at $100{ }^{\circ} \mathrm{C}$ improves the incident-photon-to-electron conversion efficiency slightly, which was attributed to improved crystallinity of the electrodeposited $\mathrm{Cu}_{2} \mathrm{O}$ and better charge collection. ${ }^{[13]}$ An efficiency of $0.47 \%$ was measured for the buffered NW cell, higher than that observed for any NW cell synthesized using the traditional solution. However, it is noted that this PCE is still less than those of the equivalent bilayer cells reported in this work and elsewhere. ${ }^{[11]}$ Thus while this novel buffering method effectively reduces the interface state density and increases the efficiency of electrochemically 
(a) bilayer heterojunction

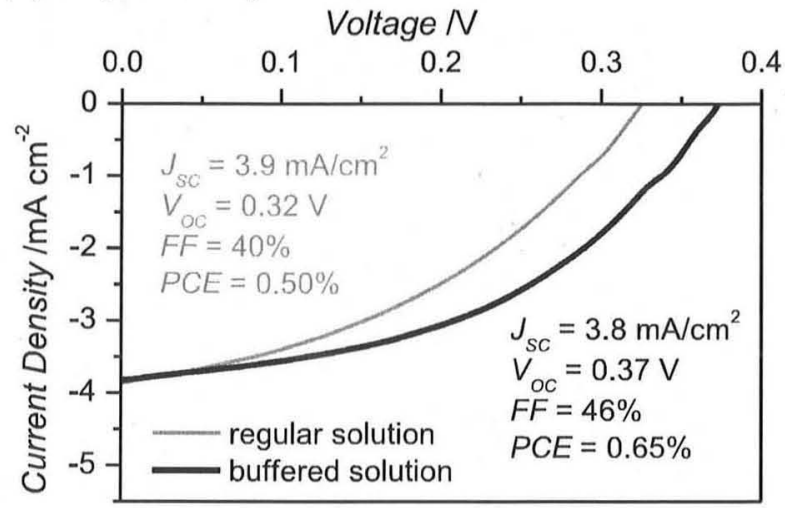

(b) nanowire heterojunction

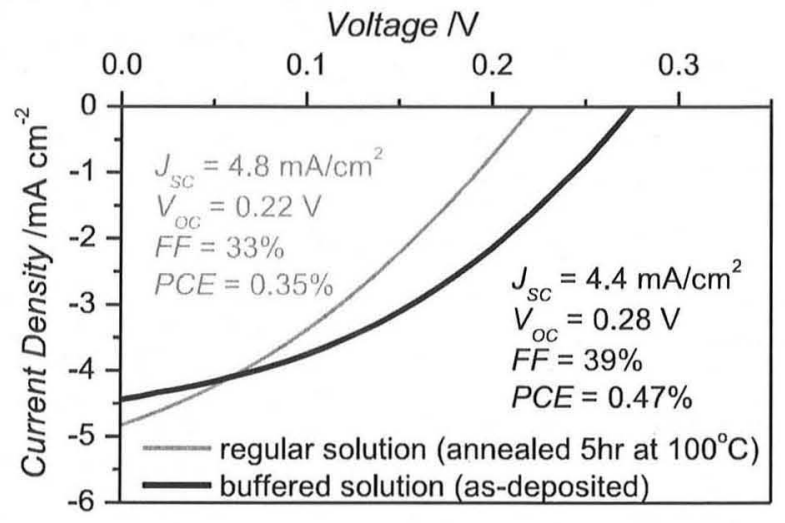

Figure 11. Current density-voltage measurements under AM 1.5G illumination for bilayer (a) and $\mathrm{NW}$ (b) $\mathrm{Cu}_{2} \mathrm{O}-\mathrm{ZnO}$ heterojunctions synthesized using regular and buffered $\mathrm{Cu}_{2} \mathrm{O}$ deposition methods.

deposited $\mathrm{Cu}_{2} \mathrm{O}-\mathrm{ZnO} \mathrm{NW}$ heterojunctions, further investigation of limitations in these NW cells is necessary.

\section{Conclusions}

A novel buffering technique has been presented to improve the stability of $\mathrm{ZnO}$ in aqueous processing solutions. A suitable quantity of sacrificial $\mathrm{ZnO}$ powder is added to the aqueous solution to attain electrochemical equilibria of dissolved zinc species. Buffering of solutions used for (i) releasing $\mathrm{ZnO}$ nanostructures from mesoporous anodic alumina templates and (ii) the electrochemical deposition of $\mathrm{Cu}_{2} \mathrm{O}$ onto $\mathrm{ZnO}$ films and nanowires was found to prevent the dissolution of the $\mathrm{ZnO}$ structures and the formation of unwanted precipitates on their surfaces. $\mathrm{Cu}_{2} \mathrm{O}-\mathrm{ZnO}$ bilayer and NW solar cells electrochemically synthesized using buffered $\mathrm{Cu}_{2} \mathrm{O}$ deposition solutions were found to have a greater resistance to unwanted recombination at their interfaces, which was attributed to a reduction in the interface state density. Enhanced open-circuit voltages and power conversion efficiencies were measured for the buffered cells under solar illumination, consistent with the larger recombination resistance observed by impedance spectroscopy.
The need for annealing of the NW devices was eliminated with the buffering method, allowing the synthesis of nanostructured heterojunction solar cells entirely from solutions near room temperature. While this work has emphasized the use of this buffering technique in the treatment of $\mathrm{ZnO}$ in basic aqueous solutions, it is equally applicable to $\mathrm{ZnO}$ in acidic mixtures and to other oxides that are unstable in aqueous solutions such as $\mathrm{BaO}, \mathrm{Al}_{2} \mathrm{O}_{3}, \mathrm{~V}_{2} \mathrm{O}_{5}$, and $\mathrm{MoO}_{3} \cdot{ }^{[18]}$ The buffering method developed in this work is a powerful technique applicable to a wide variety of functional oxides synthesized and processed in aqueous solutions.

\section{Experimental Section}

ZnO Film and Nanowire Synthesis: Commercial ITO/glass substrates (Praezisions Glas \& Optik, $14 \mathrm{~mm} \times 14 \mathrm{~mm} \times 0.7 \mathrm{~mm}$ ) were used for synthesis of the $\mathrm{ZnO}$ films and nanowire arrays and consisted of an approximately $200 \mathrm{~nm}$ ITO layer (sheet resistance less than $10 \Omega \mathrm{sq}^{-1}$ ) on soda glass. All substrates were thoroughly cleaned in an ultrasonic bath with acetone and iso-propanol for $20 \mathrm{~min}$ prior to use. For the growth of $\mathrm{ZnO}$ nanowires, a $\mathrm{Zn}$ seed layer approximately $50 \mathrm{~nm}$ thick was sputtered onto the substrates using an Emitech sputter coater.

Electrodepositions were performed using a standard three-electrode system in aqueous electrolytes of dissolved precursors. A Princeton Applied Research Model 363 Potentiostat/Galvanostat was used to supply a constant deposition potential or current. The substrates were electrically connected with an insulated wire and $\mathrm{Ag}$ paste, which was masked using Kapton polyimide tape. $\mathrm{A} \mathrm{Ag} / \mathrm{AgCl}$ reference electrode in a saturated aqueous $\mathrm{KCl}$ solution was employed, with a $6.25 \mathrm{~cm}^{2}$ inert platinum counter electrode. The sample and platinum electrodes were placed approximately $1 \mathrm{~cm}$ apart in the deposition solution and the reference electrode was placed immediately adjacent to the sample surface. The depositions were performed under computer control and the amount of charge collected at the working electrode was used to estimate the nominal thickness of material deposited. All chemicals used were reagent grade, and the water purified (resistivity greater than $16 \mathrm{M} \Omega \mathrm{cm}$ ).

Approximately $550-\mathrm{nm}$ thick $\mathrm{ZnO}$ layers were potentiostatically deposited at $-0.85 \mathrm{~V}$ versus $\mathrm{Ag} / \mathrm{AgCl}$ from a simple $\mathrm{Zn}\left(\mathrm{NO}_{3}\right)_{2}(0.08 \mathrm{M})$ solution (75\% $\mathrm{H}_{2} \mathrm{O} ; 25 \%$ ethanol by volume) at $70{ }^{\circ} \mathrm{C}$, following from previous reports. ${ }^{[22,40]}$ The nanowires were electrodeposited at $-1.0 \mathrm{~V}$ versus $\mathrm{Ag}$ / $\mathrm{AgCl}$ from a $\mathrm{ZnCl}_{2}\left(5 \times 10^{-4} \mathrm{M}\right) / \mathrm{KCl}(0.1 \mathrm{M})$ solution at $78^{\circ} \mathrm{C}$, in a similar manner to previous work. ${ }^{[23]}$ Oxygen was bubbled in the NW deposition solution throughout the deposition to ensure oxygen saturation.

$\mathrm{Cu}_{2} \mathrm{O}$ Electrodeposition and $\mathrm{NaOH}$ Etching Solutions: The standard $\mathrm{Cu}_{2} \mathrm{O}$ deposition solution consisted of $\mathrm{CuSO}_{4}(0.4 \mathrm{M}) /$ lactic acid $(3 \mathrm{M})$ at $40{ }^{\circ} \mathrm{C}$ to which $\mathrm{NaOH}(4 \mathrm{M})$ was added to adjust the $\mathrm{pH}$ to approximately 12.5. The $\mathrm{NaOH}(0.1 \mathrm{~m})$ etching solution was used at room temperature. $\mathrm{pH}$ levels were measured using an Oakton Benchtop pH 510 meter. For the buffered solutions, $\mathrm{ZnO}$ powder was added then the solutions were heated at $40{ }^{\circ} \mathrm{C}$ and stirred for several hours. A suitably large beaker was used for the stirring to ensure a shallow solution depth (less than approximately $5 \mathrm{~cm}$ ) during mixing. Again, all chemicals used were reagent grade, and the water purified (resistivity greater than $16 \mathrm{M} \Omega \mathrm{cm}$ ).

Heterojunction Synthesis: $\mathrm{Cu}_{2} \mathrm{O}$ was deposited galvanostatically at $-1.0 \mathrm{~mA} \mathrm{~cm}{ }^{-2}$ following the method of Izaki. ${ }^{[1]}$ Gold or silver contacts $\left(0.125 \mathrm{~cm}^{2}\right.$ illuminated area) were evaporated onto the $\mathrm{Cu}_{2} \mathrm{O}$ using a BOC Edwards resistance evaporator to form an ohmic contact.

Materials Characterization: SEM images were obtained using a LEO VP-1530 field-emission scanning electron microscope equipped with an EDX detector. TEM images were obtained with a leol JEM-2011 transmission electron microscope operated at $200 \mathrm{kV}$ acceleration voltage and with a FEI Titan TEM operated at an acceleration voltage of $300 \mathrm{kV}$. XRD measurements were performed using a Bruker D8 theta/ theta XRD system with $\mathrm{Cu} K \alpha$, radiation $(\lambda=0.15418 \mathrm{~nm})$ and a LynxEye position sensitive detector. Cyclic voltammetry measurements were 
performed using the same three-electrode cell used for depositions and custom-made LabView software.

Device Characterization: Impedance measurements were performed in the dark using an Agilent 4294 Precision Impedance Analyser. For each frequency scan, 201 data points were taken on a logarithmic scale and recorded using custom-made LabView software. The impedance data was fit to relevant circuit models using LEVMW complex nonlinear leastsquares fitting software. ${ }^{[35]}$

Current density-voltage measurements were performed using a Keithley 2400 SourceMeter with a custom-made LabView program. A solar simulator equipped with AM 1.5G filters was used at $100 \mathrm{~mW} \mathrm{~cm} \mathrm{~cm}^{-2}$ intensity. The illumination intensity was calibrated using an ISE Fraunhofer institute certified silicon reference diode equipped with a KG5 filter to minimize spectral mismatch errors.

\section{Acknowledgements}

KPM, AM, and JLMD would like to acknowledge the International Copper Association, Peterhouse (Cambridge), the Natural Sciences and Engineering Research Council of Canada, the Higher Education Funding Council for England, and the Gates Cambridge Trust who have funded this work. LSM and CS would like to thank the German research foundation (DFG) for funding in the Cluster of Excellence "Nanosystems Initiative Munich (NIM)". This work was also enabled by an Academic Research Collaboration Grant from the British Council Germany and DAAD. The authors would like to thank S. Schmidt and M. Döblinger for technical support on the TEM.

Note: This article was amended on February 8, 2011 to update Figure 4f from the one originally published online, which showed an incorrect scale bar.

[1] L. Schmidt-Mende, J. L. MacManus-Driscoll, Mater. Today 2007, $10,40$.

[2] M. S. White, D. C. Olson, S. E. Shaheen, N. Kopidakis, D. S. Ginley, Appl. Phys. Lett. 2006, 89, 143517.

[3] A. K. K. Kyaw, X. W. Sun, C. Y. Jiang, G. Q. Lo, D. W. Zhao, D. L. Kwong, Appl. Phys. Lett. 2008, 93, 221107.

[4] M. Law, L. E. Greene, J. C. Johnson, R. Saykally, P. Yang, Nat. Mater. 2005, 4, 455.

[5] M. Law, L. E. Greene, A. Radenovic, T. Kuykendall, J. Liphardt, P. Yang, J. Phys. Chem. B 2006, 110, 22652.

[6] N. O. V. Plank, H. J. Snaith, C. Ducati, J. S. Bendall, L. Schmidt-Mende, M. E. Welland, Nanotechnology 2008, 19, 465603.

[7] P. Ravirajan, A. M. Peiro, M. K. Nazeeruddin, M. Gratzel, D. D. C. Bradley, J. R. Durrant, J. Nelson, J. Phys. Chem. B 2006 110,7635 .
[8] L. E. Greene, M. Law, B. D. Yuhas, P. Yang, J. Phys. Chem. C 2007, $111,18451$.

[9] I. Gonzalez-Valls, M. Lira-Cantu, Energy Environ. Sci. 2009, 2, 19.

[10] C. Levy-Clement, R. Tena-Zaera, M. A. Ryan, A. Katty, G. Hodes, Adv. Mater. 2005, 17, 1512

[11] M. Izaki, T. Shinagawa, K. T. Mizuno, Y. Ida, M. Inaba, A. Tasaka, J. Phys. D: Appl. Phys. 2007, 40, 3326.

[12] B. D. Yuhas, P. Yang, J. Am. Chem. Soc. 2009, 137, 3756.

[13] K. P. Musselman, D. Iza, A. Wisnet, H. Hesse, C. Scheu, J. L. MacManus-Driscoll, L. Schmidt-Mende, Adv. Mater. 2010, 22, E254.

[14] P. Sommeling, B. ORegan, R. R. Haswell, H. Smit, N. Bakker, J. Smits, J. Kroon, J. van Roosmalen, J. Phys. Chem. B 2006, 110, 19191.

[15] Y. Li, G. W. Meng, L. D. Zhang, F. Phillipp, Appl. Phys. Lett. 2000, 76, 2011.

[16] M. J. Zheng, L. D. Zhang, G. H. Li, W. Z. Shen, Chem. Phys. Lett. 2002, 363, 123.

[17] K. Musselman, G. Mulholland, A. Robinson, L. Schmidt-Mende, J. MacManus-Driscoll, Adv. Mater. 2008, 20, 4470.

[18] M. Pourbaix, Atlas of Electrochemical Equilibria in Aqueous Solutions, Pergamon Press, 1966.

[19] T. D. Golden, M. G. Shumsky, Y. Zhou, R. A. VanderWerf, R. A. V. Leeuwen, J. A. Switzer, Chem. Mater. 1996, 8, 2499.

[20] P. E. de Jongh, D. Vanmaekelbergh, J. Kelly, Chem. Mater. 1999, 11, 3512.

[21] T. J. Hsueh, C. L. Hsu, S. J. Chang, P. W. Guo, J. H. Hsieh, I. C. Chen, Scr. Mater. 2007, 57, 53.

[22] J. Katayama, K. Ito, M. Matsuoka, J. Tamaki, J. Appl. Electrochem. $2004,34,687$.

[23] J. Elias, R. Tena-Zaera, C. Levy-Clement, J. Electroanal. Chem. 2008, $621,171$.

[24] K. Mizuno, M. Izaki, K. Murase, T. Shinagawa, M. Chigane, M. Inaba, A. Tasaka, Y. Awakura, J. Electrochem. Soc. 2005, 152, $\mathrm{C} 179$.

[25] G. Friesen, M. E. Ozsar, E. D. Dunlop, Thin Solid Films 2000, $361-$ $362,303$.

[26] H. Bayhan, A. S. Kavasoglu, Sol. Energy 2006, 80, 1160.

[27] Y. Y. Proskuryakov, K. Durose, B. M. Taele, S. Oelting, J. Appl. Phys. 2007, 102, 024504

[28] A. Niemegeers, M. Burgelman, J. Appl. Phys. 1997, 81, 2881.

[29] Impedance Spectroscopy: Theory, Experiment, and Applications, (Eds: E. Barsoukov, J. R. Macdonald), John Wiley \& Sons 2005.

[30] U. Rammelt, G. Reinhard, Electrochim. Acta 1990, 35, 1045.

[31] J. Donnelly, A. Milnes, IEEE Trans. Electron Devices 1967, 14, 63.

[32] W. A. Strifler, C. W. Bates, J. Appl. Phys. 1992, 71, 4358.

[33] K. Cole, R. Cole, J. Chem. Phys. 1941, 9, 341.

[34] G. Brug, A. Van Den Eeden, M. Sluyters-Rehbach, J. Sluyters, J. Electroanal. Chem. 1984, 176, 275.

[35] J. R. Macdonald, LEVMW Complex Nonlinear Least Squares Fitting Program 2009.

[36] W. Oldham, A. Milnes, Solid State Electron. 1964, 7, 153.

[37] A. Milnes, D. Feucht, Heterojunctions and metal-semiconductor junctions, Academic Press, 1972.

[38] S. S. Jeong, A. Mittiga, E. Salza, A. Masci, S. Passerini, Electrochim. Acta 2008, 53, 2226.

[39] G. P. Pollack, D. Trivich, J. Appl. Phys. 1975, 46, 163.

[40] K. P. Musselman, T. Gershon, L. Schmidt-Mende, J. L. MacManus-Driscoll, "Macroscopically uniform electrodeposited $\mathrm{ZnO}$ films on conducting glass by surface tension modification and consequent demonstration of significantly improved p-n heterojunctions", unpublished. 